\title{
Un género literario y teológico en formación Debates en la historia de la redacción de Gaudium et spes
}

\author{
Carlos Schickendantz • \\ Centro Teológico Manuel Larraín - Universidad Alberto Hurtado (Chile) \\ cschickend@uahurtado.cl
}

Recibido 29.09.2020/ Aprobado 07.10.2020

DOI: https://doi.org/10.46553/teo.57.133.2020.p183-216

\section{Resumen}

En la narrativa identitaria de las iglesias latinoamericanas y caribeñas del posconcilio ocupa un lugar central la importancia de la recepción de la Constitución pastoral, en particular, la metodología teológico-pastoral que asigna un rol decisivo a la contextualización en el proceso de argumentación creyente. La presente contribución ofrece un aspecto poco trabajado en la bibliografía de la región. Se trata de los debates conciliares en los que con mucha dificultad se introdujo una novedad metodológica difícil de precisar para todos los interlocutores de entonces. Las intervenciones de los padres conciliares en octubre y noviembre de 1964 muestran esa búsqueda de lo que representa una verdadera reforma de la ratio fidei en la ciencia teológica, no solo una novedad en el género literario de los documentos en toda la historia conciliar de la Iglesia.

Palabras clave: Signos de los tiempos; Método ver-juzgar-obrar; Schema XIII; Metodología inductiva

\section{A Literary and Theological Genre in the Making \\ Debates on the Redaction History of Gaudium et spes}

- El autor es doctor en teología, profesor e investigador en el Centro Teológico Manuel Larraín, Universidad Alberto Hurtado (Chile). https://uahurtado.academia.edu/CarlosSchickendantz. Este texto se enmarca en el proyecto de investigación Fondecyt Nº 1190556. 


\section{ABSTRACT}

The importance of the reception of the pastoral Constitution, especially, the theological-pastoral method that assigns a decisive role to contextualization of faith reasoning processes has a central place in the identity narrative of the post-Council phase in Latin American and Caribbean local churches. The current contribution offers a Topic that is not usually found in the available Bibliography of the region: the conciliar debates in which, with great difficulty, a novel method was introduced. The interventions of the Council Fathers in October and November 1964 show the search for what represents a true reform of the ratio fidei in theological science, and not just a novelty in the literary genre of the documents throughout the conciliar history of the Church.

Keywords: Signs of the Times; See-Judge-Act Method; Schema XIII; Inductive Methodology

\section{Introducción}

En el posconcilio latinoamericano y caribeño las comunidades eclesiales, particularmente las conferencias generales del episcopado y, también, teólogos y teólogas han construido progresivamente una narrativa identitaria propia en la cual es posible visualizar elementos estructurantes, que luego se verifican en una infinidad de publicaciones en los diferentes países y bajo distintas modalidades. Es sabido que no existe conciencia identitaria sino mediante un proceso narrativo con el cual una persona, institución o comunidad traza las líneas fundamentales de su auto comprensión, caracteriza cuáles son los rasgos que la definen, destaca sus eventos históricos decisivos, selecciona sus textos principales, en síntesis, se dice a sí misma quién es $\mathrm{y}$, al mismo tiempo, se presenta ante los demás. Naturalmente, un relato identitario es siempre parcial, limitado, puede uniformar de manera excesivamente unilateral una historia y realidad más compleja y, es claro, necesita ser revisado continuamente, readecuado y profundizado en nuevas circunstancias contextuales.

No es tarea difícil identificar algunos ingredientes esenciales que caracterizan la autoconciencia eclesial posconciliar de esta región. Acudiendo aquí al testimonio de varios teólogos de la «primera generación» del posconcilio, aproximadamente, pertenecientes a diversos países pongo de relieve uno de esos factores clave. Como 
otros líderes eclesiales y teólogos/as de la región Juan Noemi, de Chile (1942-2017), ha afirmado que el Vaticano II representó «el acta de bautismo de una teología latinoamericana», más por su planteamiento contextual en relación con el mundo de hoy, que por una enseñanza explícita acerca de la naturaleza de la teología. En ese marco, en la bibliografía del autor, es posible evidenciar la relevancia peculiar que él atribuye al influjo de la Constitución pastoral en comparación a los otros documentos del Vaticano II. Noemi afirma que Gaudium et spes 4 es «un texto que se convertirá en un verdadero programa teológico en Latinoamérica». ${ }^{1}$ Por el contrario, recuerda, "con anterioridad al Vaticano II predomina un ejercicio teológico para el cual el contexto espacial y temporal constituye una exterioridad, un accidente que no es considerado en sí mismo como determinante del teologizar. $»^{2}$

Uno de los mejores textos sobre la metodología de Gaudium et spes y su relevante y creativa recepción en el continente es el ofrecido por el jesuita argentino Juan Carlos Scannone (1931-2019) en 1995. El impacto del método en las conferencias generales del episcopado, los nuevos aspectos creativos, por ejemplo, la mayor contribución de las ciencias sociales, y su relevancia para la teología de la liberación en sus diferentes vertientes están allí bien destacados. ${ }^{3}$

El teólogo peruano Gustavo Gutiérrez, por su parte, ha escrito que «si encontrarse dentro del arco temporal del Concilio le da actualidad a Medellín, ella le viene también de haber iniciado en América Latina una forma de ver la realidad y la presencia de Dios en ella: estar atentos a los signos de los tiempos. ${ }^{4}$ De manera semejante, el historiador brasilero José Oscar Beozzo escribe en un artículo de 2008: «El método, ver, juzgar y actuar, heredado de la JOC de

1 Cf. Juan Noemi, «Rasgos, imperativos y desafíos», en Teología latinoamericana, ed. Juan Noemi; Fernando Castillo (Santiago: Centro Ecuménico Diego de Medellín, 1998), 9-93, $19-20$.

2 Juan Noemi, «Rasgos de una teología latinoamericana», en El futuro de la reflexión teológica en América Latina, ed. L. Mendes de Almeida y otros (Bogotá: CELAM, 1996), 29-74, 31.

3 Juan Carlos Scannone, «La recepción del método de Gaudium et Spes en América Latina», en La Constitución Gaudium et Spes. A los treinta años de su promulgación, ed. Juan Carlos Maccarone et al. (Buenos Aires: Paulinas, 1995), 19-49.

4 Gustavo Gutiérrez, «Actualidad de Medellín», Páginas 152 (1998): 6-17, 11. 
Joseph Cardijn, se inspiró también en la teología de los "signos de los tiempos" de la Gaudium et spes y fue el hilo conductor de todos los trabajos de Medellín ». Esas afirmaciones se enmarcan en la clara conciencia del momento fundante de la Conferencia de 1968: hay «un antes y un después en la vida de la Iglesia de este continente». 6 En ese contexto se comprende una constatación más reciente del jesuita español residente muchos años en Bolivia, Víctor Codina: Gaudium et spes es «el texto que mayor impacto ha tenido en América Latina por su invitación a auscultar y a discernir los signos de los tiempos». ${ }^{\text {? }}$

Ahora bien, no es necesario decidir cuál es el documento conciliar más influyente para verificar lo decisivo de Gaudium et spes y su forma de proceder con relación a algunas de las experiencias regionales más significativas de estas décadas. Un ejemplo importante puede verificarse en relación a la lectura popular de la Biblia. Carlos Mesters lo ha destacado con claridad: «Muchos factores contribuyeron para que se llegase a este tipo de lectura de la Biblia aquí en el Brasil». El primer factor que cita es el «trabajo de la JOC: una nueva manera de ver la revelación de Dios. El método Ver, Juzgar, Obrar trajo poco a poco una nueva manera de considerar y experimentar la acción reveladora de Dios dentro de la historia. ${ }^{8}$ En este sentido, puede decirse que la afirmación más reciente del mexicano José Legorreta es ampliamente compartida en nuestro continente: «el método ver-juzgar-actuar se tornó emblemático de la nueva forma de ser Iglesia y hacer teología en América Latina».9

5 José Oscar Beozzo, «Cuarenta años después de Medellín», Concilium 328 (2008): 133145, 137.

6 Gutiérrez, «Actualidad de Medellín», 6 .

7 Víctor Codina, «Las Iglesias del continente 50 años después del Vaticano Il», en 50 años del Vaticano II. Análisis y perspectivas, ed. Congreso Continental de Teología (Bogotá: Paulinas $2013), 81-92,84$.

8 Carlos Mesters, «A leitura libertadora da Bíblia», Medellín 88 (1996): 123-138, 129. Cf. Agenor Brighenti, «Método ver-julgar-agir», en Dicionário do Concilio Vaticano II, ed. João Decio Passos; Wagner Lopes Sanchez (São Paulo: Paulinas, 2015), 608-61 5, 608.

9 José Legorreta, Cambio e identidad de la Iglesia en América Latina. Itinerario de la eclesiología de comunión de Medellín a Aparecida (México D.F.: Universidad Iberoamericana, 2015) (edición electrónica), 255. 
En ese contexto una constatación puede hacerse. Aunque no es posible tener una mirada exhaustiva de toda la bibliografía teológica especializada del posconcilio en nuestra región, parece que una tarea no fue hecha por nuestros teólogos/as y teologías o, en todo caso, fue realizada de una manera muy marginal: un estudio sobre el mismo Concilio, su preparación, los debates en cada uno de los períodos, el lento proceso de formación de los diversos textos, la atención a las categorías en disputa, los aportes concretos fruto de la participación de actores latinoamericanos y caribeños, etc. El trabajo histórico sobre la Iglesia de Brasil de José Oscar Beozzo, por ejemplo, es ejemplar en muchos sentidos, pero representa casi una excepción. ${ }^{10}$ Parece que la narrativa identitaria continental se construyó sobre la específica recepción de Medellín, a partir de ella y, por diversos motivos, el proceso conciliar mismo, previo, quedó opacado. Naturalmente que pueden ensayarse diversas interpretaciones para explicar este hecho. Esto no significa, de ningún modo, que el Vaticano II no haya sido mayoritariamente valorado o, peor aún, que haya sido puesto en cuestión en nuestro continente, como sí se advierte, incluso hoy, en el panorama eclesial y teológico de Estados Unidos, pero un tratamiento detenido de las actas conciliares, por ejemplo, parece un trabajo extraño a la bibliografía de nuestra región.

En ese marco que, por una parte, destaca la centralidad de un documento conciliar y una metodología para la Iglesia y las teologías del continente y que, por otra, advierte un campo más o menos inexplorado en nuestros trabajos especializados se sitúa el aporte de este artículo. Deseo contribuir a la información histórica y al diálogo teológico sobre un momento clave en la emergencia de ese modo de proceder referido por Noemi, Scannone, Gutiérrez, Beozzo, Codina, Mesters que, si bien tiene sus antecedentes previos en la experiencia de la Juventud Obrera Cristiana (JOC) fundada por el belga Joseph Cardijn, adquiere una cualidad muy diferente al pretender, con muchas dificultades, estructurar un documento conciliar y, con

10 José Oscar Beozzo, A Igreja do Brasil no Concilio Vaticano /l 1959-1965 (São Paulo: Paulinas, 2005). 
él, esbozar germinalmente una forma de proceder al pensar la fe que, después del Concilio, tendrá su expresión científica, por primera vez en la teología católica universal, en la metodología de la teología de la liberación latinoamericana. ${ }^{11}$

Como es sabido, el documento sobre la Iglesia en el mundo de hoy, aprobado recién en diciembre de 1965, el día anterior a la finalización solemne del Concilio, no tuvo un texto preparatorio en la fase previa a la manera de los otros documentos. Su origen reside, más bien, en los debates de diciembre de 1962, particularmente con la intervención clave en el aula conciliar de Leo Suenens el día 4 de diciembre. El cardenal belga propuso el decisivo "plan de conjunto» vertebrado por la distinción ad intra - ad extra: «el Concilio es el Concilio 'de la Iglesia' y tiene dos partes: de Ecclesia ad intra - de Ecclesia ad extra». ${ }^{12}$ En esas semanas de diciembre y del mes de enero se dieron los primeros pasos que condujeron a producir varios esquemas durante 1963. Pero ninguno de ellos obtuvo el consenso y la aprobación para ser presentado en las sesiones conciliares del segundo período, entre setiembre y diciembre de 1963. Si bien el proceso de redacción de ese año fue muy rico en propuestas, por razones de espacio me concentro en esta contribución en el debate en el aula conciliar en las semanas de octubre y noviembre de 1964 en el que, por primera vez, la asamblea examinó un proyecto completo de documento. Incluso, debido al volumen de información, presto más atención a las intervenciones de los padres conciliares que al texto mismo del esquema que, naturalmente, sufriría muchas modificaciones en el desarrollo subsiguiente.

11 Cf. Leonardo Boff, Cómo hacer teología de la liberación (Madrid: Paulinas, 1985), 35; Agenor Brighenti, «Raíces de la epistemología y del método de la teología latinoamericana», Medellin 78 (1994): 207-254; Hans-Joachim Sander, «Theologischer Kommentar zur Pastoralkonstitution über die Kirche in der Welt von heute Gaudium et spes», en Herders Theologischer Kommentar zum Zweiten Vatikanischen Konzil. Band 4, ed. Peter Hünermann; Bernd Jochen Hilberath (Freiburg i.Br.: Herder, 2005), 581-886, 856-859.

12 Acta Synodalia Sacrosancti Concilii Oecumenici Vaticani II (Typis Polyglottis Vaticanis, 1973), I, 4, 223 (en adelante AS; se cita primero el volumen, luego, la parte y, finalmente, la página). El discurso concluyó con un aplauso de aprobación por parte de la asamblea; «Plausus Patrums (AS I, 4, 225). 
El texto enviado a los obispos para su tratamiento conciliar, que lleva por título «Schema De Ecclesia in mundo huius temporis», comienza a ser debatido en la congregación general 105 el 20 de octubre de 1964. Se trata del «schema dictum "decimum tertium" (numerus fama infelix!)», como alude en tono simpático John Wright, obispo de Pittsburgh, Estados Unidos, en su intervención del 28 de octubre (AS III, 5, 703). Consta de un prooemium y cuatro capítulos: I. De integra hominis vocatione; II. De Ecclesia Dei hominumque servitio dedita: III. De ratione christianorum se gerendi in mundo in quo viount; IV. De praecipuis muneribus a christianis nostrae aetatis implendis (AS III, 5, 115-142). A ellos se añadían los llamados $A d n e x a,{ }_{1}^{13}$ provenientes sustancialmente de los esquemas de marzo-mayo de 1963, que, en este momento de la historia de la redacción, no pertenecían propiamente al documento; aspecto debatido, precisamente, en el tercer período.

Después de la introducción del cardenal Fernando Cento, presidente de la comisión para el apostolado de laicos (AS III, 5, 201-203), y de la relatio de Emilio Guano, obispo de Livorno, Italia, en ese momento presidente de la comisión mixta responsable del esquema (AS III, 5, 203-214), tuvieron lugar las intervenciones de los padres conciliares, vía oral y escrita, las cuales se extendieron hasta la congregación general 119 del 10 de noviembre de 1964. Se cuentan, aproximadamente, unas 345 intervenciones sobre el esquema. Muchas de ellas se realizaron en nombre de varios obispos, en algún caso incluso hasta 150. Entre ellas es posible advertir poco más de 30 intervenciones de latinoamericanos y caribeños, aunque también en este caso deben incluirse las intervenciones de obispos de otros continentes a las cuales obispos de nuestra región adhirieron. Como era habitual en el debate de los documentos en el aula conciliar, primero se discutieron los aspectos generales y, luego, en un segundo momento, capitulo tras capítulo o, a veces, número tras número del texto. Aunque es cierto que esa frontera a menudo no es

13 Adnexum 1 - De persona humana in societate; Adnexum II. De matrimonio et familia; Adnexum III. De culturae progressu rite promovendo; Adnexum IV. De vita oeconomica et sociali; Adnexum V. De communitate gentium et pace. (AS III, 5, 147-201). 
clara -debate en general-debate en particular- porque con ocasión de debates precisos sobre un número o concepto se formulan no pocas veces juicios más bien globales, como es posible comprobar también aquí, en las intervenciones sobre el esquema XIII.

El documento fue votado en general el 23 de octubre con un resultado muy favorable: sobre 1876 obispos votantes, hubo 1579 placet, 296 non placet y 1 voto nulo (AS III, 5, 416). Eso significaba, en concreto, que el texto era aprobado como base del subsiguiente trabajo conciliar, naturalmente sujeto a futuras modificaciones conforme a las propuestas de los obispos en las siguientes sesiones. Este resultado representaba, a no dudarlo, el objetivo principal perseguido por los redactores.

En la presentación y análisis que sigue sobre las intervenciones en el debate no se presta atención a temáticas particulares, como matrimonio, familia, cultura, economía, etc., ni tampoco a las repetidas referencias sobre algunos conceptos o ideas puntuales, como las nociones de mundo o Iglesia, la ausencia de una explícita condena al comunismo o el pedido de un tratamiento más detenido del problema del ateísmo, la relación entre las dimensiones natural y sobrenatural, etc. Refiero a juicios más globales que atañen a la finalidad del documento, al debate acerca de sus destinatarios, al llamado género literario y estilo, al método y a la noción de signos de los tiempos que en buena medida lo simboliza, también al carácter internacional de la lectura contextual que se realiza. Constituyen perspectivas que refieren a los aspectos destacados por los teólogos latinoamericanos citados al inicio.

\section{Relatio de Emilio Guano:} «de actuali realitate in lumine theologiae»

Las actas conservan allí, además del nuevo texto del esquema, de la introducción del cardenal F. Cento y de la relatio de E. Guano, también otra relatio de Guano, probablemente el texto ya presentado en marzo de 1964 a los miembros de la comisión mixta res- 
ponsable de la redacción del esquema. Allí se advierte, entre otras cosas, que el documento elaborado en la reunión de Zúrich procura hablar de «la realidad actual a la luz de la teología (de actuali realitate in lumine theologiae): por una parte, la teología especulativa que interpreta la realidad de este tiempo y, por otra, de la teología práctica que dicta las normas para la acción de los cristianos en esta misma situación»; se trata de «la situación actual vista complexivamente (no en los detalles que tratarían los Adnexa), por tanto de las cosas positivas y de los peligros en los cuales los hombres y mujeres de hoy están involucrados, de sus ansias, de sus esperanzas». Guano reconoce claramente las importantes dificultades afrontadas en la elaboración del texto $y$, esto, «por varias razones»: la «dificultad de juzgar la difícil situación actual», el poner en evidencia adecuadamente sus principales rasgos que están en una «continua y rápida evolución». Reconoce lo «extremadamente complejo de las relaciones entre Iglesia y mundo, su misma naturaleza». El estilo y los destinatarios del esquema, una vez más, son caracterizados: un «documento estrictamente pastoral», pero advierte, «no al modo de un mensaje»; defiende su naturaleza de documento, que «habla a los católicos», aunque «también a personas no católicas y no cristianas». Por ello, argumenta, los redactores hacen uso de un modo de hablar (modo loquendi) que, si bien está «bíblicamente inspirado y es teológicamente fiel», ofrece mayor facilidad para la comprensión a las personas «de nuestro tiempo no versadas particularmente en disciplinas teológicas» (AS III, 5, 145-146).

En la relatio más extensa ofrecida de viva voz en el aula Guano caracteriza el documento, su «diferencia», incluso su «novedad», comparándolo «con las otras constituciones conciliares». Aquí no se trata de la proclamación a los cristianos y al mundo de lo que la Iglesia posee y sabe acerca de sí misma y de la revelación, de la relación en general y teórica con el mundo, ni de los medios con los que se edifica la comunidad eclesial, la predicación, la catequesis, la vida sacramental y litúrgica, etc. Todas esas «cuestiones ya han sido o están siendo tratadas en otras constituciones», por el contrario, afirma, «in hoc schemate logice transitus fit ad res et problemata, quae 
maxime animos hodie movent» (AS III, 5, 205). Más adelante, expresa: «quaestio de mundo huius temporis est essentialiter quaestio de homi$n e »\left(\right.$ AS III, 5, 211). ${ }^{14}$ De allí que, con explícita referencia a la primera encíclica de Pablo VI, Ecclesiam suam, publicada unos pocos meses antes, se promueva un diálogo con todos los seres humanos sobre sus condiciones de vida y sobre los mayores problemas de nuestro tiempo. Por este motivo, aduce, parece necesario que «estilo y lenguaje» se acomoden «al modo de sentir y hablar de las personas de nuestro tiempo», pero sin «disminuir la pureza y plenitud del mensaje evangélico». Consciente de las múltiples dificultades ya verificadas en el proceso de redacción, Guano destaca algunas: la complejidad doctrinal del asunto de la relación entre Iglesia y mundo, el no fácil «equilibrio» entre los grandes principios evangélicos y la descripción y explicación de las condiciones presentes que deben ser iluminadas por esos «principios»; también la identificación de las «condiciones de vida y tendencias que mayormente son típicas de nuestro tiempo", sin caer en una casuística o una descripción fenomenológica demasiado genérica. Responder acabadamente a los problemas planteados, como muchos esperan, no es posible. A eso se suma, la «no menor» dificultad del modo de hablar (modus loquendi), sobre todo para responder a la finalidad de la constitución adecuada a sus destinatarios: dirigirse a todos los seres humanos. La «pluralidad de visiones teológicas» existentes referidas a conceptos y argumentos tampoco puede ser minusvalorada, argumenta. Al señalar con lucidez las observaciones recibidas reaparecen preocupaciones permanentes expresadas en todo el proceso de redacción: ¿cuánta fundamentación teológica es necesaria?, ¿es preciso una mayor atención a la ley natural? La necesaria clarificación de la noción de mundo es ya historia repetida. ${ }^{15}$ También se demanda

14 Pero, como bien caracteriza el obispo de Paderborn, Alemania, Lorenz Jaeger, se trata de delinear el "nuevo tipo" de ser humano propio de este tiempo: "Hoc in contextu debemus breviter typum hominis novum huius temporis delineare, qui typus ex rationibus historicae evolutionis provenit.» (AS III, 5, 474).

15 La caracterización que E. Guano aquí realiza de esta noción, con sus diversos niveles, parece muy apropiada (AS III, 5, 209), pero los debates acerca de ella no menguarán, incluso hasta el final del Concilio. 
precisión sobre la noción de signos de los tiempos: «simul accuratior elucidatio quaeritur de sensu theologico "signorum temporum" ". Igualmente se menciona la demanda de una mayor perspectiva internacional: "Signa temporum" ne nimis sub aspectu europaeo et occidentali considerentur, universaliori aspectu aliquantulum neglecto». ${ }^{16} \mathrm{Y}$ no solo los fundamentos teológicos requerían mayor atención: «Magis sensui historiae et notioni progressus attendatur». Sin olvidar, una vez más: «Quoad formam litterariam...» (AS III, 5, 208).

El tono general de la exposición muestra que Guano era bien consciente de la profundidad y multiplicidad de asuntos que se afrontaban, las debilidades que el texto poseía, también la necesidad de ganar la buena voluntad de sus oyentes. A esa altura del proceso conciliar un rechazo del esquema hubiera significado que el Concilio no tendría como producto final entre sus documentos esta difícil, pero esperada constitución. También lo sabían los padres conciliares que dieron su aprobación en general al documento con la esperanza que el texto ganara en calidad en el camino subsiguiente.

Guano refiere al título -Schema De Ecclesia in mundo huius temporis-como una propuesta abierta sobre la que esperan sugerencias de los padres conciliares (AS III, 5, 210). Me pregunto si su repetida alusión al esquema con la palabra constitutio, también en este contexto, tiene ya un sentido técnico y preciso. No parece que, hasta ese momento de la historia de la redacción, el asunto haya tenido una conversación específica y explícita. Por el contrario, será un asunto clave en los debates de 1965.

\section{Un género literario «hasta ahora nunca usado en un Concilio»}

Un aspecto fundamental que se advierte al considerar estas dimensiones -finalidad, destinatarios, género literario, método- reside 
en que el documento, a los ojos de prácticamente todos los padres conciliares, posee un carácter inédito. No faltan lúcidas observaciones acerca de la novedad del asunto. Dos ejemplos. El obispo belga André M. Charue (Namur) afirma que el esquema tiene un género literario «hasta ahora nunca usado en un Concilio», de allí también, argumenta, la insatisfacción sobre su debilidad teológica y la necesidad de una maduración ulterior: «Hoc schema omnium schematum novissimum est, neonatum, et adhuc praematurum $\gg .{ }^{17}$ Concluye su exposición solicitando trabajo, tiempo y paciencia con un tono esperanzador; se necesita «una buena incubadora»: «Ut dixi, schema nostrum natum est praematurum, ac proinde adhuc debet habere bonam matricem («une bonne couveuse») ad opus perficiendum» (AS III, 5, 349). Desde otro ángulo puede advertirse que algunas preguntas formuladas en ese momento del debate demuestran la conciencia de la novedad; expresan perplejidad y búsqueda. «¿Es lícito a la Iglesia hablar del mundo actual como habla un moralista, un sociólogo, un culturalista, un político?», se pregunta Marcelo González Martín, obispo de Asturias, España, y expresa poco más adelante en su exposición, con un tono constructivo: «Ecclesia non est organismus sociologicus promotionis culturalis vel sociales relate ad mundum». De allí que demande más claridad en el «enfoque» del texto: «quod appareat clarius angulus visionis (el enfoque) et linea doctrinalis totius schematis» (AS III, 5, 464-468). La perplejidad manifestada no refiere solo a uno $u$ otro tema del documento, sino a su impostación global.

\section{3. ¿Un estilo impropio de un documento conciliar?}

Una manera de caracterizar la novedad y las preocupaciones reside en torno a las expresiones de «estilo» y de «género literario»

17 AS III, 5, 347: «Unde particulate omnino est schematis nostri, ut ita dicam, «genus litterarium", quod usque nunc in aliquo Concilio nondum adhibitum est. Hac de causa, aliqui Patres schema non satis theologicum aestimant, aut etiam nimis technicum iudicant. Sed quid mirum? Hoc schema omnium schematum novissimum est, neonatum, et adhuc praematurum. Nemo dubitat quominus schema maturatione egeat ut magis theologicum fiat ac simul magis concentum sensui et anxietati hodierni hominis». 
con las cuales se hablaba del esquema. El cardenal Raúl Silva Henríquez, arzobispo de Santiago, Chile, cerraba la lista de oradores la primera mañana del debate, el 20 de octubre, con un juicio positivo sobre el esquema para que continuara como base del debate conciliar. Después de aportar diversos argumentos que destacan su importancia, llama particularmente la atención sobre el «género literario»: «debería ser realmente doctrinal». Aunque, advierte, «la doctrina debería ser expuesta según un estilo y un modo adaptado especialmente a la mente de los laicos de este tiempo, explicando bien ya desde el inicio qué se entiende por los términos "mundo", "signos de los tiempos", "orden temporal", etc.» (AS III, 5, 237). ${ }^{18}$ Las opiniones negativas utilizando términos semejantes también son verificables. A juicio del obispo de Westminster, Inglaterra, John Heenan, el texto es oscuro, ambiguo, también peligroso; critica igualmente la amplitud de los destinatarios, utiliza incluso una frase que aparece repetida por varios obispos: es un estilo impropio de un documento conciliar. ${ }^{19}$ Así es, por ejemplo, la observación de Giuseppe Siri, cardenal-arzobispo de Génova, Italia: el texto «non habet sufficienter stylum documenti conciliaris sed potius cuiusdam elucubrationis» (AS III, 5, 891). En esa línea también el obispo croata Franjo Franic, de Split-Makarska. ${ }^{20}$ Pero, paralelamente, no faltan exposiciones que proponen enmiendas en orden a destacar aún más un «stylus maxime pastoralis, familiaris et omnibus accommodatus» y un orden en la exposición que parta de lo más conocido hacia lo más específico de la fe, como la de Maurice Roy, arzobispo de Québec, Canadá (AS III, 5, 322-323).

18 A la intervención adhirieron obispos de Argentina, Chile, Colombia, Uruguay, México, etc. 19 AS III, 5, 319: «Stylus quidem totius schematis piam hortationem magis quam documentum conciliare sapiti.

20 AS III, 5, 330: «Schema in genere carere videtur clara finalitate, immo et clara delimitatione extensionis materiae». La carencia de una adecuada fundamentación teológica también es destacada por Franic: «Alter defectus schematis videtur esse methodologicus, scil. ipse modus loquendi qui potius descriptivus est, sine adaequata theologica enuntiatione principiorum, quae se referunt ad problemata varia et maxima, quibus angustiatur mundus hodiernus et pro quibus mundus a Concilio illuminationem exspectat) (AS III, 5, 331). La poca claridad sobre la finalidad del esquema también aparece en Denis Hurley, arzobispo de Durban, Sud África (AS III, 5, 341-344). 
La crítica radical del cardenal Alfredo Ottaviani es muy significativa, incluso por el cargo que detentaba. Además de liderar la Congregazione del Sant'Uffizio era presidente de la comisión teológica, una de las responsables del esquema. Piensa que el texto carece de una finalidad determinada, argumentando que la tarea de la Iglesia es enseñar «autoritativamente» y no hacer descripciones consoladoras. En segundo lugar, afirma, el texto no posee una doctrina teológica suficiente. «Hinc repetitiones, confusionem inter descriptiones et principia, inter aspectos transeuntes et aspectus permanentes problematum.» (AS III, 5, 427). Cuestiona, además, lo que llama la carencia de una metodología adecuada:

\begin{abstract}
«Caret schema prudenti methodologia: nam quando, sicut in praesenti, aliquod schema conciliare utitur methodologia aequivoca vel non satis praecise, theologice, evenire potest sicut iam de facto evenit in ephemeridibus, quad ipsa doctrina Ecclesiae e. g. circa matrimonium, circa pacem, etc. vario et non recto modo intelligi possit». (AS III, 5, 428).
\end{abstract}

De manera análoga a la posición de Ottaviani, la intervención de Antonio de Castro Mayer (Campos, RJ, Brasil) concuerda también con la de Paul Meouchi, patriarca Maronita de Antioquía acerca de la «ausencia de fundamentos teológicos en el esquema» (AS III, 5, 339). Una crítica global y severa aparece igualmente en Luigi Carli, obispo de Segni, Italia (AS III, 5, 439-441), perteneciente como Castro Mayer al grupo conservador Coetus Internationalis Patrum. También la opinión de Joseph Cornelis, obispo de Lubumbashi, Congo, es muy negativa sobre la «carencia de la doctrina teológica sobre las relaciones entre Iglesia y mundo»; se trata de un documento pastoral según los autores, «¿por qué no doctrinal?» se pregunta. ${ }^{21}$ Las observaciones de Édouard Jetté, obispo de Joliette, Canadá, a propósito del tema del matrimonio y la moral conyugal, ofrecen una idea de cómo varios interlocutores imaginaban la finalidad de

21 "Schematis nostri defectus principalior videtur esse privatio doctrinae theologicae de relationibus inter Ecclesiam et mundum. Redactores quidem, ut dictum est, conati sunt documentum stricte pastorale conficere et non doctrinale. Sed quaerimus: cur non doctrinale? In hoc tempore necessaria omnino apparet doctrina de habitudine Ecclesiae ad mundum» (AS III, 5, 626). 
un concilio y, por tanto, su adecuada forma de proceder: «El rol de un Concilio es fijar principios de absoluta certeza. Los detalles de la aplicación refieren a la conciencia individual iluminada por teólogos prudentes y competentes.» (AS III, 7, 293). ${ }^{22}$

La descripción del problema planteado en términos de la tensión entre principios permanentes y aspectos contingentes es otra clave de lectura de las perplejidades o insatisfacciones. La intervención en un tono positivo de Juan Landázuri Ricketts, cardenal arzobispo de Lima, Perú, pone de relieve la relación entre los «principios eternos e inmutables» que la Iglesia posee y la dificultad de su «aplicación» a las circunstancias temporales actuales, a esas «mudables condiciones» a las que la Iglesia debe «acomodarse», sin que eso signifique un cambio en los «propios principios» (AS III, 5, 267). ${ }^{23}$ Parece ser esta una de las terminologías preferidas para la explicitación de la contextualización en aquel estadio del debate, al menos para los padres conciliares favorables al esquema.

\section{4. «Procuremos que nuestro esquema no sea un soliloquio!»}

La idea del diálogo entre la Iglesia y los seres humanos del propio tiempo como palabra clave juega a favor de los redactores del esquema; no aparece discutida en las intervenciones. Por el contrario, la expresión se repite, evidentemente estaba ya sustentada por la encíclica de Pablo VI, Ecclesian suam (agosto de 1964), pero eso no significa que, entonces, se apreciara una verdadera comunicación bidireccional. «El texto peca de exagerada timidez», no solo

22 Contra este repetido argumento de oposición a la futura Constitución, que es posible encontrar hasta muy avanzado el trabajo de su redacción, Yves Congar, no obstante sus múltiples críticas a los diversos esquemas, en mayo de 1963 defiende la inclusión de lo que aquí llama "decisiones prácticas", Mon Journal du Concile (Paris: Les Éditions du Cerf, 2002), I, 372: «El argumento basado en la tradición conciliar no es válido: no es cierto que los Concilios sólo hayan hablado de doctrina y de lo eterno».

23 Naturalmente la idea de una doctrina inmutable y su relación con lo mutable aparecía de diversas formas en las intervenciones: L. Shehan, Baltimore, Estados Unidos (AS III, 5, 350). La propuesta de dividir el esquema en dos partes, una doctrinal y otra de aplicación práctica, fue presentada por el obispo de Valencia, España, Rafael González Moralejo, con la adhesión de varios obispos de lengua hispana (AS III, 5, 381). 
desde el punto de vista «del contenido, sino también en su modo de hablar», afirma William Conway, arzobispo de Armagh, Irlanda (AS III, 5, 289) destacando el deber de instruir. La intervención de Karol Wojtyla, por ejemplo, tematiza el «método de enseñar»; propone el procedimiento "que llamamos "heurístico"», «no autoritario», gracias al cual se le "permite al discípulo encontrar la verdad casi por sus medios», de suerte que «la mente de aquellos con los que hemos hablado sea conducida a través de los argumentos»; "argumentos claros y simples a los que la sana razón asiente con facilidad», en el caso de los temas morales, «a partir de la ley de la naturaleza». ${ }^{24} \mathrm{La}$ advertencia de Wojtyla en ese contexto, más allá del método propuesto, parece adecuada, esto es, evitar un soliloquio: «Caveamus autem, ne schema nostrum soliloquium fiat!» (AS III, 5, 299). Pero, de hecho, las intervenciones muestran prevalentemente un espíritu de soliloquio, una línea unidireccional, que debe ofrecer sus propios principios - «de thesauro suo»- profundizados, y con mayor base bíblica, incluso en obispos como Leo Suenens (AS III, 5, 270), también alemanes y escandinavos favorables al esquema (AS III, 5, 510).

Un muy buen texto sobre el diálogo y sus condiciones ofrece la intervención de Adrien Gand, obispo coadjutor de Lille, Francia. «Dialogus cum hominibus fratribus nostris in hoc mundo postulat primo cognitionem praecisam mundi in qua vivimus. Quae cognitio hodie non facile acquiritur». Por su complejidad dicho conocimiento requiere de instrumentos científicos y, además, «cognitio ex corde» en orden a percibir adecuadamente los valores humanos. Se trata, probablemente, de la intervención explícita más específica acerca de la necesidad de un conocimiento «científico» fundado de la realidad actual como ingrediente del proceso de diálogo (AS III, 5, 570-572). ${ }^{25}$

24 AS III, 5, 299: «Argumenta in quaestionibus moralibus sumantur ex lege naturae». Cf. también Antonio Caggiano, Buenos Aires, Argentina (AS III, 5, 564).

25 Un reconocimiento muy positivo de la actividad científica y la libertad de investigación realiza el obispo auxiliar de Colonia, Alemania, Wilhelm Cleven (AS III, 5, 588-590). Cf. también John Wright, obispo de Pitts burgh, Estados Unidos (AS III, 5, 703). Sobre un estilo y lenguaje adecuado al conocimiento científico de nuestro tiempo, cf. igualmente Giuseppe Zaffonato, obispo de Udine, Italia (AS III, 7, 387) 
Precisa es también la intervención de Gérard Huyghe, obispo de Arras, Francia: «Non erit dialogus cum non-christianis si non existit dialogus internus cuiusque baptizati cum Spiritu Sancto». E1 diálogo «no supone primero la disposición a hablar, sino la disposición a escuchar». Esa disposición nace y se desarrolla en lo íntimo del corazón por la acción del Espíritu Santo. Y con una expresión teológica digna de notar, argumenta que es el Espíritu quien «docet nos per eventus quos vivimus aut verba quae audimus». ${ }^{26}$ ¿Se trata, quizás, de la mejor formulación de la fundamentación teológica del diálogo Iglesia-mundo en el tercer período conciliar? ¿No queda aquí fundada de la mejor manera el significado teológico de un momento inductivo en el proceso de creer y argumentar?

\section{Signos de los tiempos - ¿Categoría bíblica o más bien fenomenológica? - Método inductivo}

La categoría de signos de los tiempos en buena medida condensa, por una parte, la novedad del esquema, de su punto de partida más inductivo y, por otra, explicita también sus dificultades.

La observación metodológica del cardenal Paul-Émile Léger, arzobispo de Montreal, Canadá, el primer día de los debates, que contrasta con la forma de argumentar de cardenales que lo precedieron en la palabra como A. Liénart (Lille, Francia) y E. Ruffini (Palermo, Italia), ratifica que la forma de proceder del esquema es interesante. $Y$ precisa que los signos de los tiempos no solo son para para conocer mejor las necesidades humanas, sino que también por ellos se descubre la misma voz y voluntad de Dios. ${ }^{27}$ La interven-

26 «Nullus dialogus verus cum non-christianis sine vero dialogo interno cum Spiritu Sancto. Breviter dico. Dialogus non supponit primo dispositionem ad loquendum, sed dispositionem ad audiendum. Haec dispositio nascitur et in intimo corde evolvitur prout credamus activae Spiritus Sancti in nobis praesentiae. Ille suggerit nobis semper et docet nos per eventus quos vivimus aut verba quae audimus.» (AS III, 5, 613).

27 «In schemate opportune manifestatur cura procedendi a realitate mundi hodierni. Etenim «signa temporum» nostrae considerationi proponuntur non tantum ut homines eorumque necessitates melius cognoscantur, sed etiam ut per illa signa ipsius Dei vox et voluntas detegantun> (AS III, 5, 226-228, 227). 
ción siguiente de Julius Döpfner, Múnich, Alemania, a la que adhiere un obispo argentino (Jorge Kemerer, diócesis de Posadas) y que es positiva en relación al texto presentado, también señala este punto, pero entre los «defectos» a corregir subraya: una descripción de los rasgos presentes del mundo, «tan característicos que merezcan realmente la atención de todo el Concilio»; «cuáles son y en qué consisten precisamente hoy aquellos "signos de los tiempos" » (AS III, 5, 230).

El argumento acerca de la carencia de la perspectiva bíblica en el uso que se hace del concepto no aparece muy repetido, pero se encuentran algunos testimonios claros. Un lamento por esta carencia y una breve descripción en esa línea ofrece la intervención de Johannes Vonderach, obispo de Chur, Suiza. ${ }^{28}$ Esa relectura, a juicio de Vonderach no solo destaca la dimensión cristológica y escatológica, sino que con ella el obispo quiere poner de relieve más de lo que lo hace el esquema la «ambivalencia» de los fenómenos presentes. La crítica por la ausencia de la Escritura es enérgica también en Eduard Schick, obispo de Fulda, Alemania (AS III, 5, 733). Igualmente, varios obispos franceses, en referencia específica a los números sobre el matrimonio, invitan a reflejar en el texto las fuentes bíblicas, cuya importancia han sido destacadas en otros documentos del Concilio, por ejemplo, acerca de la Iglesia y de la revelación (AS III, 7, 394). En el caso de Vicentas Brizgys, obispo auxiliar en Kaunas, Lituania, esta carencia lo conduce a manifestar un juicio explícitamente negativo sobre el uso de la categoría. ${ }^{29}$ Propone, además, en conexión

28 "Laudandum certe est, quod in textu schematis adhibetur expressio biblica "signa temporum" et quad affirmatur Ecclesiam haec signa perscrutari debere. Dolendum tamen est, quod in texto non proceditur a profundo sensu biblico huius expressionis et quad haec neque in sensu biblico adhibetur ad diiudicanda tempora nostra.» (AS III, 5, 679).

29 "Imprimis de vocabulo "vox temporis". Dubito hoe verbum aptum esse in decreto Concilii, cum est potius ex vocabulario scriptorum sine ullo definito sensu. Quidquid sit, non puto conveniens esse hunc vocabulum elevandum esse usque ad dignitatem vocis Deì (AS III, 5, 621). De modo análogo argumenta Charles de Provenchères, obispo de Aix, Francia: «...expressio metaphorica "vox temporis" infausta videtur, cum doctrina de tempore complexa in Novo Testamento detur (eon, kairos, hora, potius quam chronos). Agitur verbi gratia de hora Passionis, de hora principis huius mundi, vel de temporibus eschatologicis eorumque signis, etc. Expressio hie adhibita non videtur sat fundata.» (AS III, 5, 629). Igualmente, Giocondo Maria Grotti, prelado nullius de Acre e Purus, Manaus, AM, Brasil (AS III, 5, 643). 
con dicha observación, modificar completamente el proemio: «primo loco ponenda sunt principia, secundum qua societas hominum ordiri debet, secundum haec principia diudicandus valor societatis hodiernae, proponenda remedia.» (AS III, 5, 621). La ausencia de la perspectiva bíblica también aparece en la intervención del cardenal Augustin Bea, palabras que incluso pueden ser interpretadas como una crítica global a la impostación inductiva del texto: el «documento no se dirige primeramente a los infieles, al mundo», sino a los creyentes, la enseñanza debe proponerse «ex fontibus fidei, non tantum ex motivis rationalibus» (AS III, 5, 273).

Si la observación sobre el defecto bíblico es correcta, se constata, no obstante, que la mayoría de los padres conciliares que refieren al tema muestran que, de hecho, compartían la concepción de Marcos McGrath, para quien los signos de los tiempos indican los rasgos que caracterizan a la condición humana en una época determinada. ${ }^{30}$ Así, por ejemplo, en la intervención de Narciso Jubany Arnau, entonces obispo de Gerona, España (AS III, 7, 296). Thomas Muldoon, obispo auxiliar de Sydney, Australia, al hablar sobre la temática de la desobediencia civil y los errores históricamente verificados de una obediencia ciega a las autoridades explicita el caso de Hitler en la línea del discernimiento de un signo de los tiempos (AS III, 7, 325). También la reflexión sobre la naturaleza de la paz de Eduardo Pironio, entonces obispo auxiliar de la Plata, Argentina, refleja esa mirada fenomenológico-sociológica de la categoría (AS III, 7, 337). Análogamente sobre el comunismo, según Paul Yü Pin, arzobispo de Nanking, China, «el mayor y más evidente signo de nuestro tiempo, aunque muy infeliz» (AS III, 5, 378).

En la intervención de Ignace Ziadé, obispo maronita de Beirut, Líbano, aparecen las dos dimensiones del concepto igualmente

30 La posición del obispo panameño está bien caracterizada por François Houtart, secretario de la subcomisión sobre signos de los tiempos presidida por Marcos McGrath creada en setiembre de 1964: "fenómenos que por su generalización y su gran frecuencia caracterizan una época y en los cuales se expresan las necesidades y las aspiraciones de la humanidad presente». Citada en Giovanni Turbanti, Un Concilio per il mondo moderno. La redazione della costituzione pastorale 'Gaudium et spes' del Vaticano II (Bologna: II Mulino, 2000), 374 nota 183. 
destacadas. Presenta quizás la reflexión más detenida sobre el concepto solicitando, ante todo, atender a su significado bíblico-teológico: «expositio magis theologica de "signis temporum" (...) oportet ut ad textus Evangelii referamus (...) sunt praecise signa adventus Domini» (AS III, 5, 535). ${ }^{31}$ Ofrece, además, la mejor descripción quizás de lo que él llama «modo inductivo» con una explícita referencia al triple momento: «videre, iudicare, agere» (AS III, 5, 534-535). ${ }^{32}$

Un apoyo decidido al punto de partida fenomenológico del esquema se encuentra también en la intervención de Josep Pont y Gol, obispo de Segorbe-Castellón, España. ${ }^{33}$ Felipe Benítez Avalos, obispo auxiliar de Asunción, Paraguay, por su parte, al referirse en nombre de 115 obispos latinoamericanos al número 24 del esquema sobre la cultura, pone de manifiesto el servicio que en América Latina ofrece la «Foederationis Internationalis Studiorum Socio-Religiosorum (FERES)». Y en ese contexto observa críticamente el carácter prevalentemente deductivo del texto: "Methodo proinde utar inductiva, uti oportet in his rebus; in nostro enim schemate, praevalet, proh dolor, stylus deductious.» (AS III, 6, 288). También la intervención de Marcos McGrath, aquí no como miembro de la comisión redactora, sino como obispo de Veraguas, Panamá, a la que adhieren más de 70 obispos, refiere al capítulo IV, pero más en general al método de todo el esquema (AS III, 7, 71-75). Así justifica que ya el proemio, siquiera de manera breve, «debet amplius describere verum statum universi mundi». Apoyándose en Ecclesiam suam advierte que este «estilo, o modo, o método, no solo afecta al modo de hablar, ni solo a los

31 De allí su petición, poco más adelante: «Optatur ut foveatur vigor propheticus populi Dei, cuius munus est hodie vivere problemata non solum ut phaenomena, sed profundius ut eventus in quibus effunditur Spiritus Domini surrectis (AS III, 5, 536).

32 Refiriéndose al capítulo IV, específicamente, Mauriche Pourchet, obispo de Saint-Flour, Francia, afirma que el «modum quasi inductivae manuductionis meliorem reputavimus». Expresa una visión positiva del esquema iniciado de esa manera: "signis temporum" sive anthropologicam mundi hodierni descriptionem» (AS III, 5, 595).

33 AS III, 5, 486: «EX his, mihi videtur, ingressus in schema deberet proferre analysim pure historicam - hodie dicitur phaenomenologica - status mundi actualis...». Una perspectiva semejante se encuentra en Pierre Marie Joseph Veuillot, obispo coadjutor de Paris: «Loquendo hominihus huius temporis, melius est non ex principiis philosophiae ac theologiae initium ducere, sed ex hominum experientia eorumque vita quotidiana, in qua diversa requisita naturae et gratiae intime coniunguntun (AS III, 5, 500). Cf. también Michel Vial, obispo de Nevers, Francia (AS III, 5 , 501); John Whealon, auxiliar de Cleveland, Estados Unidos (AS III, 5, 506). 
problemas que se tratan, sino también al modo con el cual los problemas se exponen». Estos problemas actuales de nuestro tiempo «son puntos comunes a partir de los cuales se inicia el diálogo» con el mundo, «ex ipsis signis temporum, ex ipsis maioribus problematibus homimum huius temporis». El diálogo es «verdadero» si se procede de este modo, en caso contrario hablamos antes de escuchar, respondemos antes de conocer cuáles son las cuestiones. Naturalmente, advierte, «nuestra respuesta no debe carecer ni de la luz evangélica ni de la teología católica...». Pero la doctrina, la teología, sobre todo en este esquema, «debe ser eminentemente pastoral», es decir, «aplicada a los problemas de la existencia real», reconociendo los valores del mundo actual. La comprensión de la doctrina «in connexione cum problematis hominum nostri temporis» es un momento esencial. Este «modo de exponer», que se inicia con los hechos, debe prolongarse luego en el discernimiento ulterior en cada diócesis y región.

En el caso de Cándido Rada (Guaranda, Ecuador) la posición es, en un sentido, más crítica; a su juicio debería determinarse con claridad el «objetivo» del esquema; un problema visible ya en la «ambigüedad» de su título. A la pregunta de cuál es el objeto del diálogo que se propone, Rada advierte que hay dos interpretaciones principalmente; hay que escoger una de ellas. La primera está bien caracterizada:

\footnotetext{
«Alii tenent hoe schema proficisci debere ex analysi signorum temporum, praecipua problemata hodierna detegere, praecipuas tendentias in eorum solutione; et omnium horum habita, Ecclesiae doctrinam de his variis quaestionibus, hodiernis adiunctis accommodatam, exponere.»
}

La segunda, por la cual él muestra preferencia, expresa un objeto más limitado: «Alii vero tenent schema obiectum magis limitatum sibi proponere debere, id est sensum christianum valorum profanorum, sive in genere sive in specie quoad quaedam peculiaris momenti et actualitatis». La preocupación del obispo ecuatoriano no parece radicar, ante todo, en una aproximación más o menos inductiva, destaca explícitamente el significado de comenzar una reflexión con los signos de los tiempos, o un temor de que la doctrina cris- 
tiana no resulte suficientemente explicitada, sino más bien, en lo inabarcable y «carente de unidad» de un esquema planteado en los términos de la primera interpretación, «un tratamiento imposible». Por el contrario, opina, es necesario un «esquema sintético» que evite la «superficialidad». Además, argumenta, el diálogo con el mundo moderno es tarea de todo el Concilio, no solo de este documento. ${ }^{34} \mathrm{El}$ objeto del esquema deben ser asuntos universales, por ejemplo, indica, no debe limitarse a «problemas exclusivamente europeos $u$ occidentales». Y añade un argumento referido al discernimiento local en términos de «aplicación» de «estos principios a las condiciones mudables de los tiempos y lugares». Por estos motivos, piensa que no es posible realizar un «análisis abarcativo de nuestro tiempo» como «objeto específico del esquema», sino más bien, el «verdadero objeto es el problema acerca del sentido cristiano de los valores profanos» que trasciende la peculiaridad de un tiempo y lugar determinados. ${ }^{35}$ De allí la propuesta de un nuevo título, a su juicio, más preciso: «De Ecclesiae habitudine ad valores profanos». Solicita que, con un voto de toda la asamblea, se defina el asunto principal: «Nobis obiectum schematis quam primum delimitandum est». Junto a la intervención de McGrath, la de Rada representa, quizás, la reflexión global del esquema, incluso de su metodología, más detenida de obispos latinoamericanos en esta fase de los debates. Aprueba una modalidad inductiva, aunque encuentre dificultades para precisarla, y destaca la importancia de la localización, también la responsabilidad episcopal, no solo singular, sino también de un grupo de ellos, en el discernimiento para «aplicar» principios a un contexto temporal y local singular.

34 «Dialogus itaque cum mundo hodierno non potest haberi ut obiectum huius solius schematis, sed totius Concilii, immo totius vitae Ecclesiae» (AS III, 5, 658).

35 «Singulorum vero episcoporum, vel episcopalium coetuum sit haec principia mutabilibus conditionibus temporum et locorum applicare. Hae de causa nobis opportunum non videtur analysim nostri temporis complexive sumpti ut obiectum specificum huic schemati assignare. Eius vero obiectum sit problema de sensu christiano valorum profanorum, quod, quamvis hodie prima vice sollemniter agitatum, tamen hodierna et localia adiuncta transcendit.» (AS III, 5, 659). 
La intervención de Alexandre Renard, obispo de Versailles, Francia, completamente dedicada a destacar lo relevante de la opinión pública y, en ese contexto, el significado de los medios de comunicación social en la configuración cultural, pone de relieve de una manera muy directa la importancia y la precedencia del conocimiento de la realidad: ese «reconocimiento precede lógicamente a la actualización del mensaje».

«Frente al mundo, la Iglesia busca medios cada vez más eficaces para transmitir el mensaje evangélico. Para ello, debe conocer el mundo y darse a conocer a él. De hecho, es importante ver las realidades humanas -ideologías, situaciones sociales, mentalidades, prejuicios, centros de interés- que constituyen el campo de apostolado dado para la Iglesia en un período determinado. Este trabajo de "reconocimiento" precede lógicamente a la actualización del mensaje». (AS III, 7, 343-347).

En este contexto un punto particular puede observarse. Las expresiones, en cierto modo audaces, del número 2 del esquema - In voce ergo temporis vocem Dei audire oportet ita ut in luce fidei praesentes opportunitates et miseriae hominum conscientiis concretum caritatis mandatum adumbrent» (AS III, 5, 117)- reciben pocos comentarios explícitos, mayormente referencias generales en unos pocos casos, $^{36}$ a menudo positivas, como la de Endre Hamvas, (Kalocsa), quien habla en nombre de diez obispos de Hungría, también reclamando precisiones como Paul Gouyon (Rennes, Francia), Félix Romero Menjibar (Jaén, España); ${ }^{37}$ el auxiliar de Colonia, Alemania,

36 Cf. por ejemplo, Josef Stimpfle, Augsburg, Alemania (AS III, 5, 324), Sebastião Soares de Resende, Beira, Mozambique (AS III, 5, 327). La intervención de este obispo de Mozambique ofrece, además, un potente párrafo sobre Iglesia y pobreza. Cf. igualmente Antoine Haucalt, Saint-Boniface, Canadá: «Ecclesia dignoscens vocem Dei in humanitate operantis. Ecclesiae... est humiliter dignoscere vocem operationemque Dei, iam aliquomodo patentes in valoribus humanis, in conatibus et incoeptis huius mundi. Ecclesiae est praesentiam atque actionem Dei detegere, et manifestius proclamare» (AS III, 5, 541). Cf. también el brasilero Henrique H. G. Trindade, Botucatu, SP (AS III, 5, 553), René Fourrey, Belley, Francia, signos de los tiempos y pobreza (AS III, 5, 555); Alberto Carinci, Boiano-Campobasso, Italia (AS III, 5, 623). La expresión signa temporum aparece 5 veces en el esquema presentado (nn. 2, 14, 19, 20,25) y otras 5 en los Adnexa; siempre en relación a la descripción de hechos y al servicio de un procedimiento inductivo, sin referencias a citas bíblicas.

37 Cf. AS III, 5, 344: "Signa temporum" in ultimis decenniis apparuerunt omnino nova. His perspectis, Ecclesia Christi aeterna, missionem ad omnem aetatem et universos homines acceptans et explens, cursum et evolutionem rerum prudenter perscrutatur et in hoc schemate applicat ad solvendum et salvandum principium Paulinum: "Omnia probate, quad bonum 
Augustinus Frotz, poniendo de relieve particularmente la transformación en la vida de las mujeres (AS III, 5, 459). Un texto significativo pertenece a Antonio de Castro Mayer (Campos, RJ, Brasil) que solicita que se aclare «en qué sentido se afirma vox temporis vox Dei»; $y$, con una categoría muy importante -revelatio- pregunta inquisitivamente: «Numquid vox temporis nova Dei revelatio est, qua Ecclesia Christi duci debeat?» Parece que Castro Mayer es el único padre conciliar que formula la novedad en estos términos, en su caso, con una perspectiva de reprobación. ${ }^{38}$

Las opiniones de los obispos latinoamericanos, en su mayoría, son positivas en relación al esquema en general, ${ }^{39}$ destacan, a menudo, aspectos más bien particulares a aclarar o profundizar: Pablo Muñoz Vega (aux. Quito, Ecuador) la acción común entre cristianos y no cristianos (AS III, 5, 332-338), Sergio Méndez Arceo (Cuernavaca, México) la actividad política y la libertad y dignidad de la persona (AS III, 5, 481-483; III, 5, 609-612), etc. Pero también refieren a las perspectivas globales antes referidas. Alberto Devoto (Goya, Argentina) destaca en sentido positivo el «modo de hablar»: «Aunque en cada esquema, la doctrina contenida es siempre el elemento principal, sin embargo, en éste sobre la Iglesia en el mundo de este tiempo, el modo de hablar tiene también una gran importancia, de tal manera que el esquema en verdad sea un instrumento para comenzar un diálogo o un coloquio con el mundo actual». De allí que afirme que «quizás el esquema requiere este modo de hablar completamente propio, y hasta diverso de los que se aplican en los otros esquemas» (AS III, 5, 451).

est, tenete!"». Cf. George Beck, obispo de Liverpool (AS III, 5, 360); Paul Gouyon, obispo de Rennes (III, 5, 405); Félix Romero Menjibar, obispo de Jaén (AS III, 5, 409), Thomas Cooray, obispo de Colombo, actual Sri Lanka (AS III, 5, 446); Marius Maziers, auxiliar de Lyon, (AS III, 5, 479); Joze Pogacnik, Ljubljana, Eslovenia (AS III, 5, 525); varios obispos de Indonesia (AS III, 5, 684).

$38 \mathrm{El}$ texto de Castro Mayer se encuentra en un volumen del cuarto período conciliar donde, como apéndice, se incluyen intervenciones escritas referidas al esquema de 1964: AS IV, 2, 1029-1034, 1029.

39 Cf. por ejemplo, además de los ya citados, Eugenio De Araujo Sales, San Salvador de Bahía, Brasil (AS III, 5, 450). 


\section{6. "Non est unus, sed plures "mundi", in quibus Ecclesia contemporanea vivit»}

Una perspectiva creciente en la historia de la redacción de Gaudium et spes también se refleja en esta fase del debate en varios testimonios: la conciencia de la complejidad del contexto geográfico-cultural aparece, progresivamente, como una dimensión esencial. Karol Wojtyla, por ejemplo, afirma el 21 de octubre: «Al decir 'mundo' tengamos siempre en mente al hombre que vive en diversos 'mundos", bajo diversos sistemas económicos, sociales y políticos. De este asunto se trata en este esquema» (AS III, 5, 300). ${ }^{40}$ De allí su observación sobre el título, que usa «mundo» en singular: «son muchos "mundos" en los que la Iglesia contemporánea vive y actúa... Esta "pluralidad de mundos" en un único mundo no se expresa suficientemente ni consta en el esquema». ${ }^{41}$ Se trata a no dudarlo de una de las expresiones más lúcidas sobre esta perspectiva en ese momento del debate conciliar, aunque el esquema completo que inmediatamente propone en nombre de los obispos polacos (AS III, 5, 300-314) parece adolecer de los mismos defectos, por lo menos, que los que Wojtyla advierte en el esquema oficial presentado al inicio de los debates. La intervención del obispo de Guinea, Raymond-Marie Tchidimbo (Conakry), es muy elocuente también: el esquema puede ser adecuado para Europa, incluso América, «sed non satis pro tertia parte mundi $i{ }^{42}$ Varios obispos africanos demandan

40 Cf. también Paul J. Schmitt, obispo de Metz, Francia (AS III, 5, 406-408).

41 AS III, 5, 299: "Oportet bene considerate, quod titulus "Ecclesia in mundo huius temporis" sensum analogicum prae se fert. Etsi enim verum sit dicere "mundum" in quo exsistit Ecclesia esse unum, nihilominus - respectu habito condicionum vitae humanae - non est unus, sed plures "mundi", in quibus Ecclesia contemporanea vivit et operatur, quibus etiam in schemate XIII vult adloqui. Haec pluralitas "mundorum" in unico mundo non satis exprimitur nec sentitur in schemate». Este argumento aducían, también, quienes solicitaban una condena explícita del comunismo: casi la mitad de la humanidad actual está bajo el influjo de esta doctrina, así el argentino G. Bolatti: «Haec est vera realitas praesentis status mundi» (AS III, 5, 395). Análogamente con la petición de condena al laicismo por el obispo auxiliar de Montevideo, M. Balaguer (III, 5, 435).

42 AS III, 5, 369: «Homines ad quos dirigitur dare enumerantur: primum catholici, deinde ornnes habitantes terrae. Ego quidem Africanarum gentium difficultatum mentionem non legi, quae sunt subevolutio (le sous-developpement), colonisatio, discriminatio ex stirpe seu colore; et non amplius structurarum societatis novellae descriptionem.» Cf. también Sergio Méndez Arceo, Cuernavaca, México (AS III, 5, 481); varios obispos del Uruguay (AS III, 5, 512); François Marty, obispo de Reims, Francia (AS III, 5, 547). 
un texto menos occidental, con mayor atención a su contexto regional: André Perraudin, Obispo de Kabgayi, Ruanda (AS III, 7, 332), Dieudonné Yougbaré, obispo de Koupéla, Burkina Fasso (AS III, 7, 384), Paul Zoungrana, Ouagadougou, Burkina Faso (AS III, 7, 391). Refiriéndose al matrimonio y en especial a los derechos de la mujer, Elias Zoghby, obispo melquita greco católico de Baalbek, Líbano, destaca la pluralidad de situaciones que deben ser reconocidas (AS III, 7, 389). También refiere a esta debilidad Henri Routhier, vicario apostólico de Grouard, Canadá; se trata de un asunto no «suficientemente considerado» en el esquema: «de pluralitate culturarum» (AS III, 7, 349).

\section{Ampliar y profundizar el «trabajo de reconocimiento»}

En línea con las observaciones anteriores acerca del pluralismo de situaciones, es posible individuar otro aspecto positivo en las intervenciones: ponencias de muy buena calidad dedicadas completamente a un tema singular, importante, que enriquece el «trabajo de reconocimiento que precede lógicamente a la actualización del mensaje» solicitado por el obispo de Versailles, Alexandre Renard, en el texto antes citado. Algunos ejemplos. Sobre la temática del racismo la intervención de Patrick O’Boyle, obispo de Washington, en nombre de todos los prelados de Estados Unidos, es muy significativa (AS III, 5, 726-728). Sobre ese mismo tema, en un estilo comprometido y apasionado, es significativa la intervención escrita de Dominic Ekandem, obispo de Ikot Ekpene, Nigeria (AS III, 5, 454-455). Sobre la dignidad de las mujeres y el derecho a la participación en la vida pública Gerard-Marie Coderre, Saint-Jeande-Quebec, Canadá, en nombre de 40 obispos de Canadá y de otros países, ofrece una muy buena reflexión..$^{43}$ En relación a la importancia de la educación básica en América Latina, un escándalo por el

43 «Scopus meus est proponendi quad in schemate melius in luce ponatur mulierem personalitatem propriam ei a Deo ipso datam habere et propterea munus in societate humana et in Ecclesia valde specificum et amplius necessarium ab ea adimplendum esse» (AS III, 5, 728). 
analfabetismo, con números muy precisos brinda la intervención de Leónidas Proaño, obispo de Riobamba, Ecuador (AS III, 6, 269-272). Si a la exposición de Proaño se suma la de Felipe Benítez Avalos, obispo auxiliar de Asunción, Paraguay, puede constatarse que se han ofrecido muchos datos acerca de la realidad continental. La demanda de humanidad y de justicia con las personas migrantes tiene también una excelente reflexión en unas intervenciones de Franjo Šeper, Zagreb, Croacia (AS III, 6, 452; III, 7, 355). Ernest John Primeau, obispo de Manchester, Inglaterra, llama la atención sobre la urbanización: «Observamos con preocupación que el documento en discusión no toma nota formal de ese fenómeno que los estudiosos contemporáneos estudian como urbanismo» (AS III, 5, 489-491). La reflexión sobre el turismo como signo de este tiempo y medio de conocimiento intercultural también es relevado; se trata de un texto de Giuseppe Garneri, obispo de Susa, Italia, al cual adhieren 87 obispos de Europa, Asia y América Latina (AS III, 5, 577-580). Sobre temas de justicia y pobreza hay muy buenos textos; un ejemplo es la intervención de Raúl Silva Henríquez, Santiago, Chile, el 27 de octubre de 1964 (AS III, 5, 565-567). De modo análogo la temática del hambre, del ateísmo con toda su complejidad, naturalmente sobre el comunismo, pero igualmente sobre la complejidad del mundo de la agricultura y de la justicia en los intercambios comerciales, sobre la guerra justa y la carrera de armamentos, etc. Los debates de la tercera sesión ofrecen un panorama multicolor y reflejan, más de lo que a menudo se supone, la sensibilidad social y cultural que motivaba a muchos protagonistas.

El significado de la futura Gaudium et spes y de todos los afanes por llevar adelante este proyecto parecían ser advertidos. Un proyecto «tan nuevo y tan difícil» requería más tiempo, un cuarto período conciliar en 1965, como solicitaban representantes de 23 conferencias episcopales y de grupos de conferencias de los cinco continentes en una carta a Pablo VI en octubre de 1964: «Consideramos que este esquema XIII, ahora esperado con impaciencia por la opinión pública en muchos países, es de capital importancia para la labor pastoral emprendida por el Concilio» (AS III, 5, 508-509). 
Al cierre de los debates, el 10 de noviembre de 1964, Emilio Guano realiza una breve y positiva evaluación de las intervenciones de esos 20 días en el aula conciliar. Recuerda la idea acerca de los destinatarios del documento, reconoce con franqueza que no hay una única opinión en la asamblea y, en ese contexto, repite su idea propuesta al inicio de los debates: "genus litterarium huius constitutionis aliud esse ac genus litterarium constitutionis dogmaticae v.g. de Ecclesia». Justifica el mantenimiento del lenguaje y el estilo ya adoptado acudiendo una vez más a los destinatarios universales. También hace un balance positivo del orden del esquema, su enfoque inicial, su punto de partida: «Ordo schematis. Optima videtur haec propositio, ut habeatur in initio schematis amplior quidam prospectus conditionis mundi huius temporis.» (AS III, 7, 83). Queda abierto el espacio, explicita, para un discernimiento acerca de qué aspectos de la condición humana actual incluir, cuáles aspectos destacar más, etc. Evidentemente el debate de esas semanas había sido extremadamente enriquecedor desde este punto de vista.

\section{Reflexiones finales}

Con la votación de aprobación general del esquema en la congregación general 108 del Concilio del 23 de octubre de 1964 quedaba ratificado un cambio de metodología en el esquema que había sido decidido a fines de noviembre de 1963 cuando, en el desarrollo de la redacción, por segunda vez en ese año se acuerda elaborar un texto completamente nuevo. Con un esquema diferente al romano -marzo-mayo de 1963- y al de Malinas/Lovaina -setiembre de 1963-, Jacques Ménager (Meaux, Francia), miembro de la comisión para el apostolado de los laicos, presentó el 15 de diciembre de 1963 un proyecto con tres partes. Con sugerencias recibidas él preparó un nuevo Proyecto de plan para el esquema XVII, el cual proponía un primer capítulo sobre la actitud abierta y dispuesta a escuchar que la Iglesia debía mantener hacia el mundo, y sobre la atención hacia los «signos de los tiempos» ofreciendo un relevamiento de 
ellos; seguía un segundo capítulo, más teológico, con la «respuesta de Dios» impostado a la luz de la creación y de la salvación; finalmente, un tercer capítulo titulado: «Consecuencias para la Iglesia y para sus miembros», aplicaciones concretas de tales principios a las cuestiones suscitadas que se articulaba en torno a tres deberes: presencia, diálogo, servicio de la Iglesia. ${ }^{44}$ Es interesante aquí la observación de Evangelista Vilanova: según esta perspectiva, en este nuevo esquema no se trataba simplemente de estimular una visión optimista de la Iglesia en relación al mundo moderno, sino también la de «asignar a las realidades terrenas, como tales, un valor de "lugar teológico" o fuente de teología». Además, añade Vilanova: el principio de los signos de los tiempos «implicaba un cambio de metodología con respecto a las redacciones anteriores. En efecto, el método doctrinal y teológico que éstas habían utilizado, era de carácter deductivo. En cambio, el esquema de Zúrich proponía una exposición de tipo inductivo. $\gg^{45}$ Esta perspectiva adquirirá una nueva concreción y mayor visibilidad con la introducción de la Exposición introductoria en el esquema de 1965, todavía inexistente en el tercer período conciliar.

La tensión entre una comprensión de la categoría de signos de los tiempos interpretada en un sentido fenomenológico-sociológico y otra más consciente de su raíz bíblica, cristológica, mesiánica y escatológica ha sido advertida en pocas intervenciones, pero se ha hecho explícita. En los redactores del Schema presentado a la asamblea en octubre de 1964 prevaleció, sin duda, la primera de ellas. Este debate condicionará fuertemente el uso de la noción en el cuarto período conciliar, hasta amenazar incluso su inclusión en el texto final del Concilio. Como es sabido, la categoría está ausente en el Schema que ingresa al debate conciliar en setiembre de 1965, en buena medida, debido a esta tensión no resuelta. En cualquier caso, esta cuestión irresuelta con dicha categoría símbolo, no pondrá en 
cuestión en la fase conciliar sucesiva la estructuración inductiva del documento, aunque siempre estará en debate su sentido, sus implicancias y su profundidad.

La importancia de la encíclica Ecclesiam suam de Pablo VI (6 de junio de 1964), muy frecuentemente citada en las intervenciones de los obispos en 1964, es de apreciar. Con ella el término y la idea de diálogo tenía asegurada una presencia en el futuro documento. Incluso las posturas más conservadoras, que destacaban unilateralmente el deber de enseñanza que la Iglesia tiene respecto del mundo, acuden a ella para sostener sus argumentos. Pero la adquisición de la palabra no significaba que esa idea, que, en principio, dignifica también al interlocutor -en este caso, el mundo, las realidades históricas reconocidas como signos de los tiempos- modificara un predominante soliloquio - de la Iglesia hacia el mundo- que incluso Wojtyla, como hemos citado, y otros advierten, sin corregirlo propiamente. Pero, siquiera de manera imperfecta hay una novedad metodológica que se abre paso con dificultad y sin precisión: el aprendizaje que la Iglesia hace a partir de las experiencias históricas en orden a su propia autocomprensión y a la inteligencia del evangelio que representa una verdadera novedad actitudinal y que busca plasmarse en la estructura misma del documento. Y. Congar lo explicitaba en un artículo en esas semanas de noviembre de 1964: después de reconocer que el "género literario es nuevo", afirma que "quien dice "signo de los tiempos" confiesa que tiene alguna cosa que aprender del tiempo mismo». ${ }^{46}$ Quizás puede decirse que, con escasa ayuda de los teólogos de entonces, y mayormente gracias a la sensibilidad pastoral de muchos padres conciliares un texto conciliar iba a delinear una reforma en la ratio fidei no verificada en esos términos no solo en los documentos en la historia de los concilios, sino tampoco en la misma ciencia teológica como tal. La expresión recién citada del historiador español Vilanova, necesitada de ulteriores precisiones, lo pone en evidencia: se trataba de 
«asignar a las realidades terrenas, como tales, un valor de "lugar teológico" o fuente de teología.» ${ }^{47}$ Ningún padre conciliar pudo (podía) formular la novedad emergente en esos términos técnicos. Dicha noción -lugar teológico o fuente de teología- no aparece ni en el esquema oficial ni en ninguna de las intervenciones orales o escritas en el curso del debate en el aula conciliar de 1964. Incluso hoy necesita ser explicada. La expresión acerca de la «historia como lugar teológico» tendrá un enorme éxito en la bibliografía posterior de este continente, pero si es verdad que ella indica una novedad, también esconde múltiples interpretaciones necesitadas de clarificación que, incluso, pueden diluir el profundo significado teológico de un momento inductivo en el proceso de argumentación en la ciencia teológica. Se trata de una transformación en la ratio fidei, ${ }^{48}$ que solo pocos años después Y. Congar advertirá como «un nuevo capítulo de epistemología teológico-pastoral», ${ }^{49}$ como «una forma relativamente nueva de teología», ${ }^{50}$ y que es clave para explicar el proceso posconciliar de América Latina y El Caribe, como se destacó en la introducción. El debate de 1965, posterior a la fecha en que se concentra esta contribución, sobre el inédito título de Constitutio pastoralis dado al Schema XIII, discusión inexistente todavía en el proceso conciliar en 1964, revelará con un poco más de claridad, de manera ineludible, la novedad en la forma de proceder concretada solo de modo germinal.

47 Cf. Carlos Schickendantz, «Autoridad teológica de los acontecimientos históricos. Perplejidades sobre un lugar teológico», Teología 115 (2014): 157-183.

$48 \mathrm{Cf}$. Carlos Schickendantz, «Un cambio en la ratio fidei. Asociación (aparentemente ilícita) entre principios teológicos y datos empíricos», Teología y Vida 57 (2016): 157-184. La preocupación del posteriormente lefebvriano obispo Antonio de Castro Mayer (Campos, RJ, Brasil) que solicitó la aclaración: «en qué sentido se afirma vox temporis vox Dei»; preguntando críticamente: «Numquid vox temporis nova Dei revelatio est, qua Ecclesia Christi duci debeat?» (AS IV 2,1029 ) necesita un discernimiento más detenido del que a menudo se hace en bibliografía latinoamericana al calificar de revelación la "nueva" palabra de Dios en la historia. Cf. Jorge Costadoat, «Novedad de la Teología de la Liberación en la concepción de la revelación», Teología 124 (2017): 27-45.

$49 \mathrm{Cf}$. Carlos Schickendantz, «Un nuevo capítulo de epistemología teológico-pastoral. Aportes a la comprensión de los signos de los tiempos», Atualidade Teológica 58 (2018): 133-158.

$50 \mathrm{Cf}$. Carlos Schickendantz, «Una forma relativamente nueva de teología. La recepción de la transformación metodológica de Gaudium et spes en Estados Unidos», Estudios Eclesiásticos 95, $372(2020): 113-152$. 


\section{Bibliografía}

Acta Synodalia Sacrosancti Concilii Oecumenici Vaticani II (Typis Polyglottis Vaticanis, 1970ss.).

Beozzo, José Oscar, A Igreja do Brasil no Concílio Vaticano II 19591965. São Paulo: Paulinas, 2005.

Beozzo, José Oscar, «Cuarenta años después de Medellín», Concilium 328 (2008): 133-145.

Boff, Leonardo, Cómo hacer teología de la liberación. Madrid: Paulinas, 1985.

Brighenti, Agenor, «Raíces de la epistemología y del método de la teología latinoamericana», Medellín 78 (1994): 207-254.

Brighenti, Agenor, «Método ver-julgar-agir». Páginas 608-615 en Dicionário do Concílio Vaticano II, ed. João Decio Passos; Wagner Lopes Sanchez. São Paulo: Paulinas, 2015.

Codina, Víctor, «Las Iglesias del continente 50 años después del Vaticano II». Páginas 81-92 en 50 años del Vaticano II. Análisis y perspectivas, ed. Congreso Continental de Teología. Bogotá: Paulinas 2013.

Congar, Yves, Diario del Concilio. Tercera sesión. Barcelona: Estela, 1965.

Congar, Yves, Mon Journal du Concile. Paris: Les Éditions du Cerf, 2002.

Costadoat, Jorge, «Novedad de la Teología de la Liberación en la concepción de la revelación», Teología 124 (2017); 27-45.

Gutiérrez, Gustavo, «Actualidad de Medellín», Páginas 152 (1998): 6-17. Legorreta, José, Cambio e identidad de la Iglesia en América Latina. Itinerario de la eclesiología de comunión de Medellin a Aparecida. México D.F.: Universidad Iberoamericana, 2015. (edición electrónica).

Mesters, Carlos, «A leitura libertadora da Bíblia», Medellín 88 (1996): 123-138.

Noemi, Juan, «Rasgos de una teología latinoamericana». Páginas 29-74 en El futuro de la reflexión teológica en América Latina, ed. L. Mendes de Almeida y otros. Bogotá: CELAM, 1996. 
Noemi, Juan, «Rasgos, imperativos y desafíos». Páginas 9-93 en Teología latinoamericana, ed. Juan Noemi; Fernando Castillo. Santiago: Centro Ecuménico Diego de Medellín, 1998.

Sander, Hans-Joachim, «Theologischer Kommentar zur Pastoralkonstitution über die Kirche in der Welt von heute Gaudium et spes». Páginas 581-886 en Herders Theologischer Kommentar zum Zweiten Vatikanischen Konzil. Band 4, ed. Peter Hünermann; Bernd Jochen Hilberath. Freiburg i.Br.: Herder, 2005.

Scannone, Juan Carlos, «La recepción del método de Gaudium et Spes en América Latina». Páginas 19-49 en La Constitución Gaudium et Spes. A los treinta años de su promulgación, ed. Juan Carlos Maccarone et al. Buenos Aires: Paulinas, 1995.

Schickendantz, Carlos, «Autoridad teológica de los acontecimientos históricos. Perplejidades sobre un lugar teológico», Teología 115 (2014); 157-183.

Schickendantz, Carlos, «Un cambio en la ratio fidei. Asociación (aparentemente ilícita) entre principios teológicos y datos empíricos», Teología y Vida 57 (2016): 157-184.

Schickendantz, Carlos, «Un nuevo capítulo de epistemología teológico-pastoral. Aportes a la comprensión de los signos de los tiempos», Atualidade Teológica 58 (2018); 133-158.

Schickendantz, Carlos, «Una forma relativamente nueva de teología. La recepción de la transformación metodológica de Gaudium et spes en Estados Unidos», Estudios Eclesiásticos 95, 372 (2020): 113-152

Turbanti, Giovanni, Un Concilio per il mondo moderno. La redazione della costituzione pastorale 'Gaudium et spes' del Vaticano II. Bologna: Il Mulino, 2000.

Vilanova, Evangelista, «La intersesión (1963-1964)». Páginas 297419 en Historia del Concilio Vaticano II. Vol. III. El Concilio maduro, ed. Giuseppe Alberigo. Salamanca: Sígueme, 2006. 
